\title{
Studies on the Nutritional Value of Tempeh
}

\author{
III. Changes in Biotin and Folic Acid Contents during \\ Tempeh Fermentation.
}

\author{
Kiku Murata, Teijiro Miyamoto, Etsuko KokUfu \\ AND YUKIKo SANKE ${ }^{1}$ \\ Food and Nutrition Laboratory, Faculty of Science of Living, \\ Osaka City University, Sumiyoshi-ku, Osaka (Post No.558)
}

(Received August 26, 1970)

\begin{abstract}
Changes in biotin and total folic acid activities in tempeh during fermentation with Rhizopus oligosporus were investigated. It was found that contents of biotin and total folate compounds in tempeh were 2.3 and 4-5 times higher than those in unfermented soybeans, respectively.
\end{abstract}

It has been reported $(1,2,3)$ that tempeh, a fermented soybean product made by the action of Rhizopus on cooked soybeans, produces some vitamins of $\mathrm{B}$ group, i.e., riboflavin, nicotinic acid, vitamin $B_{6}$, pantothenic acid, but no thiamine (4). In the series of studies on the nutritional value of tempeh, changes in contents of these vitamins during tempeh fermentation have been investigated by the present authors. However, studies had not yet been made with biotin and folic acid. This paper deals with changes in biotin and folic acid activities during tempeh fermentation.

\section{EXPERIMENTAL AND Results}

\section{Materials}

Samples of tempeh fermented for 24, 48, and 72 hours each, and of unfermented soybeans were prepared according to the method as previously reported (4).

\section{Analytical Methods}

Biotin- Biotin was determined by a microbiological assay with Lactobacillus arabinosus 17-5 according to the method of Niimura (5) as modified by the technique presented in Ass. Office. Agr. Chemists (6). Conditions to be employed for hy- drolysis of tempeh and unfermented soybean samples were examined to find a suitable concentration of $\mathrm{H}_{2} \mathrm{SO}_{4}$, and time length for autoclaving. As shown in Figure 1, the highest value of biotin was obtained with $4 \mathrm{~N} \mathrm{H}_{2} \mathrm{SO}_{4}$ when the samples were heated at $121^{\circ}$ for 60 minutes. Under the conditions of $4 \mathrm{~N}$ $\mathrm{H}_{2} \mathrm{SO}_{4}$ and $121^{\circ}$, the highest value was obtained when heated for 90 minutes, as shown in Figure 2. From these results it was found that the following procedure was the most adequate to be employed for hydrolysis of samples of tempeh and unfermented soybeans: About $0.2 \mathrm{~g}$ of samples were heated with $5 \mathrm{ml}$ of $4 \mathrm{~N} \mathrm{H}_{2} \mathrm{SO}_{4}$ under $15 \mathrm{lb}$. at $121^{\circ}$ for 90 minutes. The filtrates of the hydrolysates were adjusted to $\mathrm{pH} 6.0$ for the bioassay.

Changes in biotin content of tempeh during fermentation are shown in Figure 3, where tempeh samples fermented for $0,24,48$ and 72 hours are designated as D-1, D-2, D-3 and D-4, respectively.

Folic Acid - Free and conjugated forms of folate compounds in tempeh and unfermented soybean samples were measured microbiologically by using Lactobacillus casei and Streptococcus faecalis $\mathrm{R}$. Two tenth of a gram of the lyophilized samples were boiled with $5 \mathrm{ml}$ of $0.1 \mathrm{M}$ phosphate buffer $(\mathrm{pH}$ 7.0) for 5 minutes on a water bath, cooled, and filtered. The filtrate was used for the microbioassay of the free folate compounds. For determination of the total folate compounds, $5 \mathrm{ml}$ of the filtrate were

\footnotetext{
1 村田希久，宮本悌次郎，国府悦子，三家由喜子。
} 


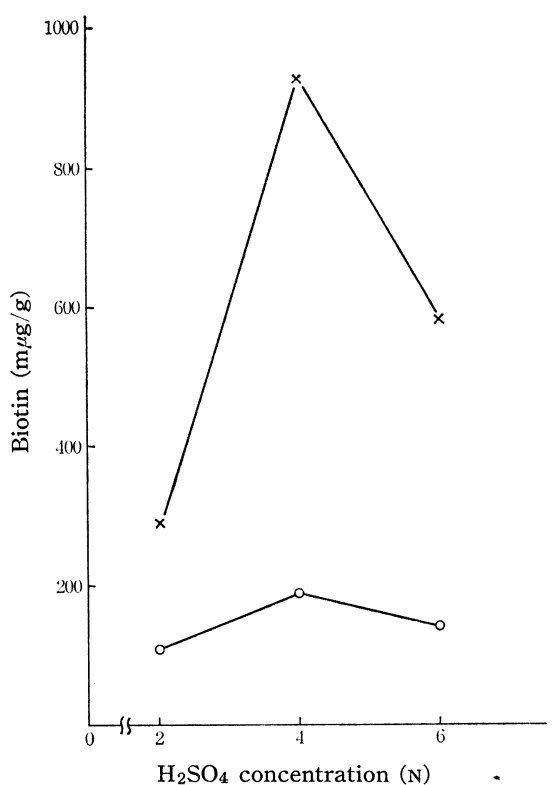

FIG. 1 Hydrolytic condition of samples for biotin determination

$-\mathrm{O}-$, soybeans; $-\times-$, tempeh. Hydrolysis : heating at $121^{\circ}$ under $15 \mathrm{lb}$. for $60 \mathrm{~min}$.

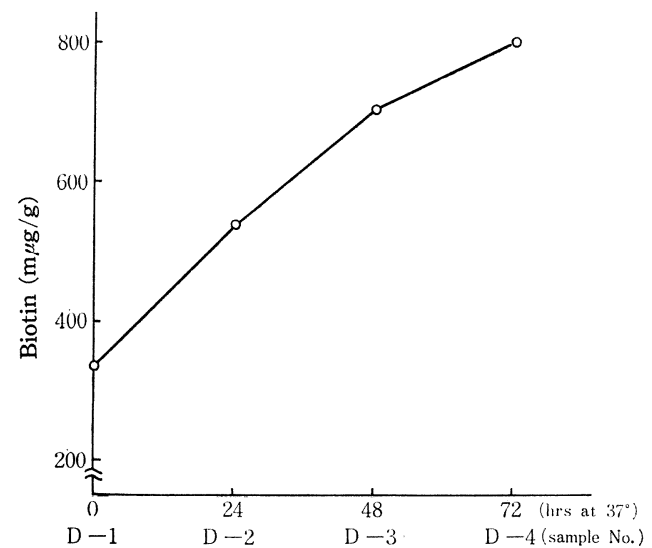

FIG. 3 Changes in biotin content of tempeh dur. ing fermentation

treated at $37^{\circ}$ overnight with $2 \mathrm{ml}$ each of hog kidney and chicken pancreas conjugases and $5 \mathrm{mg}$ of cysteine hydrochloride. The reaction mixture was filtered, made up to a definite volume with distilled water, and filtered again. The hog kidney and chicken pancreas conjugases were prepared by the method of Iwai $(7,8)$. The bacteria were maintained in a General Preservation Medium of Lactobacillus "Nissan" purchased from Nissui Chemical

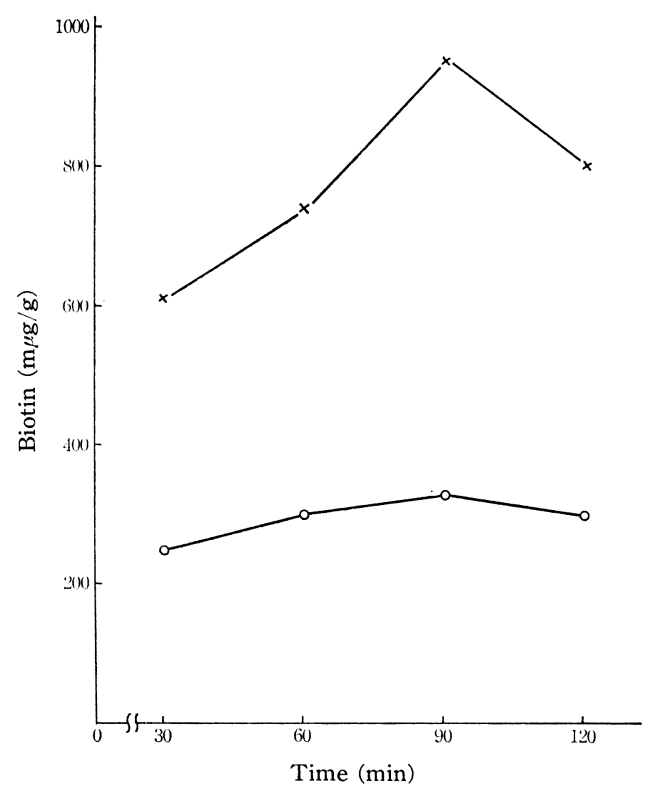

FIG. 2 Hydrolytic condition of samples for biotin determination

$-\mathrm{O}-$, soybeans; $-\times-$, tempeh. Hydrolysis : heating at $121^{\circ}$ under $15 \mathrm{lb}$. with $4 \mathrm{~N}_{2} \mathrm{SO}_{4}$

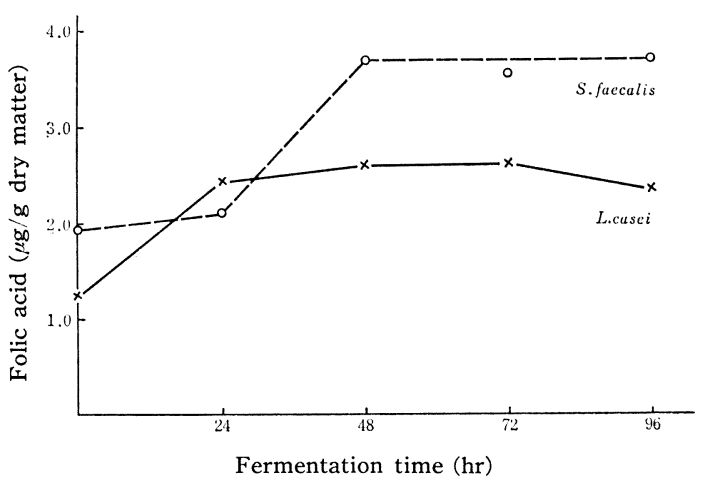

FIG. 4 Changes in activity of folic acid of tempeh treated with conjugase

Industries Ltd. A General Inoculation Medium of Lactobacillus "Nissan" from the same company was used for preparation of the inoculum. A uniform medium for the assay of $\mathrm{B}$ vitamins employed by Iwai (9) and a medium fortified with variouts amounts of casamino acid and peptone (treated both with Norit) were utilized for bioassay of folic acid.

When the assay medium of Iwai was used, assay with $S$. faecalis of tempeh fermented for 48 hours 


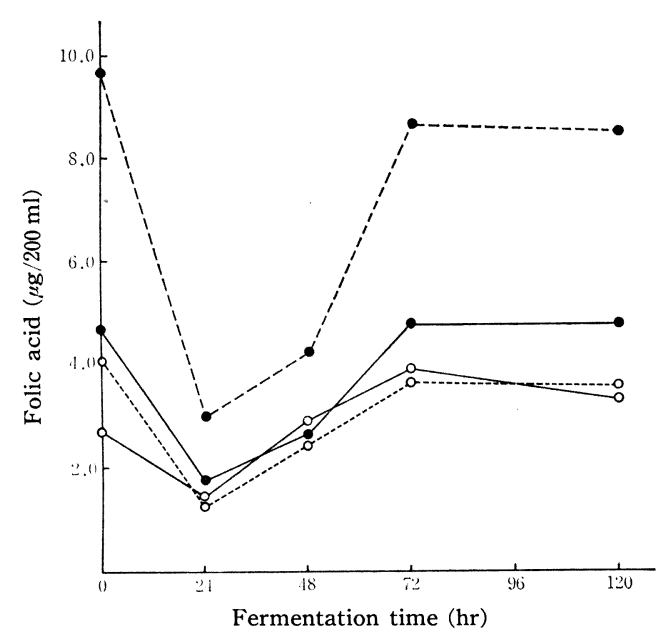

FIG. 5 Folic acid activities of culture medium of the Rhizopus estimated with S. faecals or $L$. casei

20 times dilution $S$. faecalis $R \bullet--\bullet$ L. case $i$ -..- 250 times dilution $S$. faecalis $R$

L. casei $\mathrm{O}-\mathrm{O}$

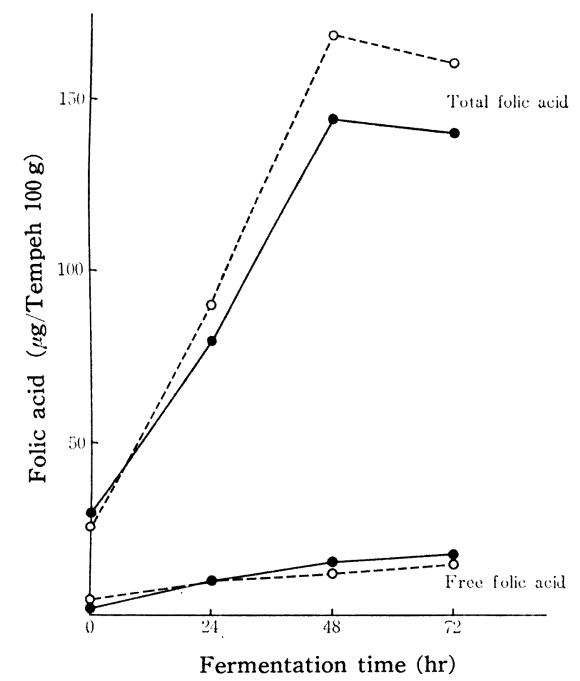

FIG. 7 Changes in folic acid activities of tempeh during fermentation

-, L. casei; .., S. faecalis $R$.

or more gave higher values of folate compounds than with L. casei, as shown in Figure 4. It was slso observed that while the value with $S$. faecalis was not consistent with that with $L$. casei when culture medium of the Rhizopus (10) was diluted 20 times, they were approximately similar when sample was diluted 250 times, as ahown in Figure 5.

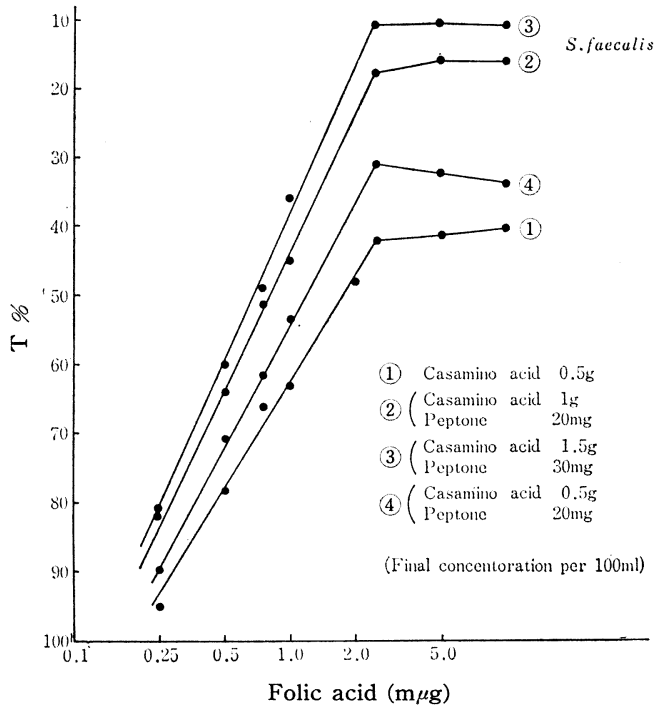

FIG. 6 Standard curves of folic acid in uniform and fortified media

From these results it was thought that growth of $S$. faecalis kept in our laboratory might be promoted in the medium forified with casamino acid and peptone. As shown in Figure 6, the medium (3) fortified with $1.5 \mathrm{~g}$ casamino acid and $30 \mathrm{mg}$ peptone to $100 \mathrm{ml}$ of the final medium showed highest growth of the bacteria and was used for the bioassay.

Filtrate of tempeh extract and the filtrate after treated with conjugases of hog kidney and chicken pancreas were provided for bioassay with $S$. faecalis or L. casei in the fortified medium to measure changes in the free and total folate compound contents in tempeh during fermentation, respectively. As shown in Figure 7, the value of total folate compounds assayed with $S$. faecalis was not appreciably different from that obtained with $L$. casei. The content of total folate compounds in tempeh fermented for 48 hours was 4-5 times higher than that in unfermented soybeans.

\section{Discussion}

Increase of total folate compounds during tempeh fermentation might be due to release of folate compounds, present in soybeans as bound forms, by action of some enzymes of Rhizopus, or due to de novo formation of these compounds by Rhizopus. The production of riboflavin and biotin by Rhizopus 
oligosporus, but not thiamine, was reported by the present authours (10). Synthesis of analogues of folic acid with Rhizopus oligosporus has been investigated in this laboratory and will be reported elsewhere.

\section{ACKNOWLEDGMENT}

This research has been financed in part by a grant from the United States Department of Agriculture under P. L. 480 and a fund from Vitamin B Researeh Committee. The authours express their thanks for this support.

\section{REFERENCES}

1. Steinkraus, K. H., Yap, B. H., Van Bauren, J. P.,
Providenti, M. I., and Hand, D. B., Food Research, 25, 777 (1960).

2. Roelofsen, P. A., and Talens, A., J. Food S'i., 29, 224 (1964).

3. Steinkraus, K. H., Hand, D. B., Van Buren, J. P., and Hackler, L. R., Proc. Conf. Soybean Products for Protein Human Food, p. 75 (1961).

4. Murata, K., Ikehata, H., and Miyamoto, T., $J$. Food Sci, 32, 580 (1967).

5. Niimura, T., Vitamins, 12, 106 (1957).

6. Method of Analysis of Ass. Offic. Agr. Chemists, p. 826 (1954).

7. Iwai, K., Vitamins, 10, 372 (1965).

8. Iwai, K., Luttner, P. M., and Toennies, G., $J$. Biol. Chem., 239, 2365 (1964).

9, Iwai, K., Okinaka, S., and Yokomizu, H, Vitamins, 35, 387 (1967).

10. Murata, K., Miyamoto, T., and Taguchi, F., J. Vitaminol., 14, 191 (1968). 